\section{Acidentes do trabalho em pescadores artesanais da região do Médio Rio Araguaia, Tocantins, Brasil}

\author{
Work-related accidents in traditional \\ fishermen from the Medium Araguaia \\ River region, Tocantins, Brazil
}

Domingos Garrone Neto ${ }^{1}$
Ricardo Carlos Cordeiro ${ }^{2}$
Vidal Haddad Jr. ${ }^{3}$

\footnotetext{
1 Instituto de Biociências, Universidade Estadual Paulista, Botucatu, Brasil.

2 Faculdade de Ciências Médicas, Universidade Estadual de Campinas, Campinas, Brasil.

3 Faculdade de Medicina de Botucatu, Universidade Estadual Paulista, Botucatu, Brasil.

Correspondência D. Garrone Neto Departamento de Zoologia Instituto de Biociências, Universidade Estadual Paulista. C. P. 549 Botucatu, SP 18618-970, Brasil. garroneneto@yahoo.com
}

\begin{abstract}
This is a cross-sectional study of work-related accidents among traditional fishermen in the Medium Araguaia River region of Tocantins, Brazil. From June to August 2002, fishermen from the Municipality of Araguacema were interviewed about the organization of their work activities and work-related accidents during the previous six months. Of the 92 participating fishermen, 56 reported having suffered a workrelated accident (annual incidence was 82.6\%). Some $95.7 \%$ of those interviewed did not regularly pay social security insurance as self-employed workers and were not aware of their social rights and duties. For fishermen reporting accidents, this proportion was $98.2 \%$. Approximately 23.0\% had another work activity, mainly as construction workers (47.6\%) or sport-fishing guides (23.9\%). Injuries inflicted by aquatic animals were the main form of accidents (about 86.0\%). From these results, it is apparent that accidents from aquatic animals are an important health hazard, in some cases causing temporary work incapacity.
\end{abstract}

Occupational Accidents; Workers; Aquatic Fauna; Incidence

\section{Introdução}

Os acidentes do trabalho constituem um importante problema de saúde pública no Brasil visto sua elevada freqüência e gravidade. Por acometerem principalmente pessoas jovens e em idade reprodutiva, acarretam, além de sofrimento para os trabalhadores acidentados e seus familiares, graves conseqüências sociais e econômicas 1,2 .

Dados da Organização Internacional do Trabalho (OIT) estimam que anualmente ocorram cerca de 1,1 milhão de óbitos em todo o mundo decorrentes de acidentes do trabalho ou doenças ocupacionais, sendo as mortes provocadas por quedas, colisões de veículos, choques elétricos, neoplasias, entre outras, algumas das causas imediatas conhecidas 3 .

No Brasil, são imprecisos os dados sobre esses agravos. Sabe-se, entretanto, que os trabalhadores sem vínculo empregatício formal representam mais da metade da força de trabalho do país, o que amplifica a falta de informações sobre a ocorrência e as características dos acidentes do trabalho em nosso meio 4,5 .

Os acidentes do trabalho ocorridos entre os trabalhadores com registro em carteira do trabalho regido pela Consolidação das Leis Trabalhistas (CLT), exceto para algumas categorias profissionais, são contabilizados pelo Ministério da Previdência e Assistência Social (MPAS), o qual possui um sistema de registro bastante deficiente 1,6. 
Apenas no ano de 1998, o MPAS registrou 401.254 acidentes do trabalho ocorridos entre os trabalhadores cobertos pelo Seguro Acidente do Trabalho (SAT), excluindo dessas estatísticas os trabalhadores autônomos e domésticos, funcionários públicos estatutários, subempregados, muitos trabalhadores rurais, entre outros 7 .

Considerando que a população coberta pelo SAT nos anos 90 correspondia a cerca de 30,0\% da população economicamente ativa e que mesmo entre os trabalhadores cobertos pelo SAT existam níveis elevados de subnotificação, conclui-se que não haja informações suficientes para caracterizar a distribuição dos acidentes sofridos pelos trabalhadores brasileiros, sobretudo daqueles que habitam os lugares onde as assistências médica e previdenciária são precárias, como as cidades ribeirinhas e vilarejos do interior do país 8 . Nesses locais, grande parte das pessoas trabalha por conta própria e sem carteira assinada, o que favorece a não notificação de acidentes, impossibilitando sua estimativa e controle.

A pesca profissional artesanal em água doce ilustra bem essa situação. Reconhecida pela Marinha desde o ano de 1940 e regulamentada pelo Decreto de Lei 221 no ano de 1967, a profissão emprega milhares de pessoas em todo Brasil, as quais sobrevivem da captura e venda do produto pescado, muitas vezes em condições precárias de habitação e saneamento 9,10.

De acordo com a legislação previdenciária, os profissionais da pesca se dividem em quatro categorias: o empresário empregador, o empregado, o pescador artesanal e o cooperado. O empregado precisa ter a Carteira de Trabalho e Previdência Social (CTPS) assinada e sua contribuição é feita pela empresa onde trabalha; o empresário e o cooperado recolhem para a Previdência Social como contribuintes individuais. O pescador artesanal, como segurado especial, também precisa recolher, devendo comprovar que exerce a pesca individualmente ou em regime de economia familiar e que está cadastrado em colônia ou federação de pescadores 11 .

A condição de segurados especiais assegura aos pirangueiros ou pescadores de anzol, como são chamados os pescadores profissionais artesanais de água doce, o acesso ao SAT oferecido pelo Plano de Benefícios da Previdência Social 11. Esse fato, ainda desconhecido por muitos pescadores, minimiza as inúmeras dificuldades enfrentadas no dia-a-dia da atividade pesqueira, visto essa ser reconhecidamente uma das profissões mais perigosas existentes, expondo seus trabalhadores a uma série de situações de risco todos os dias. Possíveis naufrágios, temporais e encontro com espécies peri- gosas de animais constituem algumas das adversidades do cotidiano da atividade 10,12.

Recentemente, o Instituto Brasileiro do Meio Ambiente e dos Recursos Naturais Renováveis (IBAMA), por intermédio do Relatório de Estatística da Pesca, revelou que com o esgotamento e diminuição de alguns estoques pesqueiros, muitos pescadores tentam compensar a situação indo cada vez mais longe, permanecendo mais tempo nos locais de pesca e menosprezando as condições adversas do meio 13 .

Apesar desses dados referirem-se principalmente à pesca profissional artesanal marinha, esse aumento da jornada de trabalho também tem sido observado na pesca profissional de água doce, a qual tem passado por situações semelhantes devido à poluição e ao represamento dos rios 9 .

O resultado dessas alterações no ambiente de trabalho dos pescadores atua como um importante fator de risco para a ocorrência de acidentes na categoria, fato que também vem sendo observado em outras profissões, como a dos trabalhadores do campo, por exemplo. Esses profissionais, pela crescente necessidade de uma maior produção de alimento e devido à desvalorização dos produtos comercializados nas propriedades, agravadas pelo aumento do custo da produção, têm aumentado seu tempo de atividade de trabalho, favorecendo, assim, uma elevação do número de acidentes 14 .

Na pesca profissional artesanal, a situação não é diferente. Devido a pressão econômica a que os pescadores profissionais artesanais estão sujeitos (devido principalmente aos baixos rendimentos resultante da ação de atravessadores, os quais impõem baixos preços pelo pescado), os pescadores têm estendido cada vez mais suas jornadas de trabalho, tanto no que diz respeito ao tempo de trabalho, quanto à distancia percorrida para alcançar os cardumes.

Em nosso meio, estudos sobre acidentes do trabalho baseiam-se principalmente em dados secundários, o que, pode limitar o conhecimento mais amplo desse tipo de agravo. O Sistema CAT, por referir-se apenas aos trabalhadores com direitos previdenciários e os atestados de óbitos e prontuários, muitas vezes preenchidos de maneira indevida, não permitem a real mensuração do problema ${ }^{15}$. Ademais, a ausência de estudos sobre as condições de vida e saúde de pescadores profissionais artesanais de água doce no Brasil e a necessidade do entendimento dessas características para a elaboração de programas educativos e assistenciais, torna imprescindível a realização de pesquisas na área, sobretudo sob o ponto de vista da saúde 
ocupacional, a qual não dispõem de informações dessa natureza.

O presente estudo relata acidentes de trabalho ocorridos entre pescadores profissionais artesanais da região do Médio Rio Araguaia, Tocantins, Brasil, estimando sua incidência e estabelecendo sua relação com fatores sócioeconômicos e ocupacionais.

\section{Método}

Um estudo de delineamento transversal foi realizado de junho a agosto de 2002 no Município de Araguacema, que na língua tupi significa "lugar de águas do Araguaia" (araguaia - rio das araras; cema - passagem, travessia). Esse povoado está localizado no noroeste do Estado de Tocantins, na região do Médio Rio Araguaia, a $49,6^{\circ} \mathrm{W}$ de longitude e $8,9^{\circ} \mathrm{S}$ de latitude.

A escolha de Araguacema para a realização do estudo baseou-se em sua localização geográfica e nas características dos profissionais da pesca que atuam no local, além da oferta de apoio logístico para a execução do trabalho de campo, como alojamento e transportes terrestre e aquático. Situada às margens do rio Araguaia e em uma região de transição entre dois grandes ecossistemas, o Cerrado e a Amazônia, Araguacema possui uma das colônias de pesca mais organizadas do Estado do Tocantins, além de possuir uma infinidade de cursos d'água ao seu redor, o que favorece a existência de uma diversidade elevada de organismos aquáticos e sugere intensa atividade pesqueira no local durante o ano todo.

Para a população de estudo, foram selecionados os pescadores profissionais artesanais com registro na Associação dos Pescadores de Araguacema - Colônia ASPESCA, cujo critério de inclusão baseou-se na Classificação Brasileira de Ocupações de 2002 16, a qual os inclui na família 6.311 e os define como "aqueles que capturam diversos tipos de pescado de água do$c e$, de acordo com regulamentação regional e federal, preservando matas ciliares e ambiente aquático; providenciam documentação de pesca, aprontam e conduzem embarcações, planejam pesca e preparam material para sua efetivação; realizam despesca; beneficiam e comercializam pescado".

Essa ocupação é exercida por trabalhadores que trabalham por conta própria, em equipe ou não, sem supervisão. A atividade é realizada a céu aberto, em horários irregulares, sujeitos à variação climática. $\mathrm{O}$ acesso ao trabalho é livre, sem exigência de escolaridade ou formação profissional. Quando é exigida experiência anterior, ela se caracteriza por menos de um ano 16 .
Os dados foram coletados utilizando-se questionários semi-estruturados individuais, onde foram levantadas as características sóciodemográficas e ocupacionais dos pescadores, além das informações sobre as pessoas que relataram ter sofrido acidente nos últimos seis meses, incluindo o período das entrevistas.

O questionário empregado no estudo foi elaborado pelos autores e continha as seguintes variáveis: sexo, cor, idade, escolaridade (em anos de estudo), renda mensal estimada (em Reais), tempo de profissão, duração da jornada de trabalho (horas/dia), exercício de atividade laboral paralela, situação previdenciária e descrição da atividade. Além disso, perguntava-se se o pescador sofreu um ou mais acidentes durante sua jornada de trabalho nos últimos seis meses. Em casos afirmativos, obtinha-se a descrição pormenorizada do acidente (em caso de mais de um acidente sofrido no período, era descrito o considerado mais grave pelo pescador), que incluía: causa imediata do acidente, hora, dia, mês, local e condições em que o acidente ocorreu, região anatômica atingida, sinais e sintomas decorrentes, tempo transcorrido entre o momento do acidente e a procura por atendimento médico, se houve ou não a realização de tratamento popular e como o caso evoluiu.

Para a classificação dos acidentes, utilizouse a definição de acidentes do trabalho adotada pelo MPAS, que os considera como "aqueles que ocorrem no trajeto casa-trabalho-casa (trajeto) ou durante o exercício da atividade profissional (típico), provocando lesão corporal ou perturbação funcional que causem perda ou redução, temporária ou permanente, da capacidade para o trabalho" 7 .

O trabalho de campo foi realizado por um dos autores (D. G. N.), que permaneceu alojado no Município de Araguacema para a realização das entrevistas e do acompanhamento da rotina de trabalho dos pescadores, como as atividades de pesca, despesca e comércio. Nesses casos, em algumas vezes foi necessário permanecer acampado com os pescadores para melhor documentar as situações desejadas.

As entrevistas foram realizadas por intermédio de inquéritos domiciliares, bem como de entrevistas com pescadores no porto da cidade de Araguacema, ocasiões onde esses trabalhadores eram informados sobre os objetivos do trabalho e convidados a participar da pesquisa após tomarem conhecimento e assinarem o termo de consentimento livre e esclarecido, em atendimento à Resolução 196/96 do Conselho Nacional de Saúde do Ministério da Saúde. 
A tabulação dos dados obtidos por meio das questões fechadas foi realizada utilizando-se o programa Microsoft Excel versão 2000, onde as variáveis foram ordenadas e suas freqüências e distribuições, obtidas.

A proporção de incidência dos acidentes foi calculada dividindo-se o número de pessoas que referiram ter sofrido acidente, pelo número total da população estudada durante o mesmo período, sendo projetada a estimativa para um ano. Não foram calculados intervalos de confiança para a incidência porque se trabalhou com toda a população de pescadores, tratando-se, portanto, de um estudo censitário e não amostral.

É oportuno ressaltar que, embora a maioria dos estudos transversais seja utilizada para estudos de prevalência, o fato de os acidentes serem eventos circunscritos no tempo, possibilita a identificação de casos incidentes 2,17.

Os dados sobre as atividades que os entrevistados exerciam no momento dos acidentes e os primeiros socorros realizados nessas ocasiões foram agrupados em categorias para melhor organização das respostas, enquanto os trechos das entrevistas registrados com o auxílio de gravador foram transcritos e digitados, mantendo o máximo de fidedignidade à linguagem dos entrevistados.

\section{Resultados}

Durante o período do estudo, 102 pescadores profissionais artesanais possuíam registro na Colônia ASPESCA. Devido aos benefícios oferecidos aos associados (dos quais o principal é o pagamento de salário aos pescadores que permanecerem inativos durante o período de reprodução dos peixes da região), todos os pescadores profissionais de Araguacema são registrados na associação. Desse total, 92 pescadores puderam ser localizados e convidados a participar do estudo. Não houve recusas ou desistências e as dez perdas observadas foram devido a não localização dos trabalhadores. Na Tabela 1 são apresentadas as características sociodemográficas e ocupacionais dos pescadores profissionais artesanais da Colônia ASPESCA.

Dos 92 pescadores profissionais artesanais que participaram do estudo, 56 relataram ter sofrido no mínimo um acidente do trabalho nos últimos seis meses, incluindo o período das entrevistas. A proporção de incidência de acidentes do trabalho obtida para a população estudada foi de $85,9 \%$ ao ano.

Sobre a situação previdenciária dos entrevistados que mencionaram ter sofrido aciden- te, apenas $1,8 \%$ estava com suas contribuições e documentações em dia. Os demais pescadores disseram não estar totalmente cientes sobre seus direitos e obrigações previdenciárias.

Os tipos e as causas imediatas dos acidentes do trabalho relatadas pela população estudada, os períodos do dia no qual as injúrias ocorreram, as atividades exercidas pelos pescadores no momento dos acidentes, as regiões anatômicas atingidas pelas lesões e o manejo dos acidentes, são apresentados na Tabela 2 .

As lesões por animais do ambiente aquático foram as principais causas imediatas de acidentes referidas, perfazendo um total de $86,0 \%$ dos casos (Tabela 3). Outras causas imediatas foram relatadas: cortes com facas ou tesouras $(5,0 \%)$, lesões provocadas por anzóis $(3,0 \%)$, acidentes com redes ou tarrafas $(2,0 \%)$, traumas por barco a remo $(2,0 \%)$ e lesões por motor de barco $(2,0 \%)$. Todos os acidentes foram classificados como "típicos" por terem ocorrido durante o exercício da atividade laboral.

A distribuição dos períodos do dia onde as pessoas referiram ter sofrido acidente foi semelhante. No período da manhã, $35,7 \%$ das pessoas disseram ter se acidentado. Pescadores que sofreram acidentes no período vespertino somaram $30,4 \%$, enquanto aqueles que relataram ter sofrido algum tipo de lesão durante a noite corresponderam a $32,1 \%$.

A maioria dos pescadores estava retirando peixes das redes ou anzóis quando se acidentou $(46,4 \%)$. O relato de acidentes por pescadores que estavam armando ou recolhendo equipamentos de pesca aconteceu em $25,0 \%$ dos casos. Acidentes em pescadores que manipulavam ou transportavam peixes mortos, operavam ou conduziam embarcações ou preparavam iscas, foram relatados em 12,5\%, 14,3\% e $1,8 \%$ dos casos, respectivamente.

As regiões anatômicas mais atingidas pelas lesões, segundo os entrevistados, foram os membros superiores $(48,2 \%)$, os membros inferiores $(39,3 \%)$ e outros, como a cabeça, o pescoço e o tronco $(12,5 \%)$.

Quanto à procura por atendimento médico, apenas $12,5 \%$ dos pescadores procuraram alguma Unidade de Saúde para tratar as lesões. Nesse grupo, o tempo decorrido entre o momento do acidente e o início do tratamento das lesões variou de três horas a vinte dias $(\mathrm{Md}=$ 4hs), sendo o Hospital Municipal de Araguacema o local onde o atendimento médico foi realizado.

Entre os $87,5 \%$ dos pescadores que não procuraram atendimento médico após sofrerem acidente, $65,3 \%$ realizaram algum tipo de tratamento popular. Para os pescadores que rela- 
Características sócio-demográficas e ocupacionais dos pescadores profissionais artesanais da Colônia ASPESCA.

Araguacema, Tocantins, Brasil, 2002.

\begin{tabular}{|c|c|c|c|c|}
\hline \multirow[t]{2}{*}{ Variável } & \multicolumn{2}{|c|}{ População estudada } & \multicolumn{2}{|c|}{$\begin{array}{l}\text { Acidentados nos } \\
\text { últimos } 6 \text { meses }\end{array}$} \\
\hline & $n$ & $\%$ & $\mathrm{n}$ & $\%$ \\
\hline \multicolumn{5}{|l|}{ Sexo } \\
\hline Masculino & 86 & 93,5 & 51 & 91,1 \\
\hline Feminino & 6 & 6,5 & 5 & 8,9 \\
\hline \multicolumn{5}{|l|}{ Cor } \\
\hline Branco & 24 & 26,1 & 10 & 17,9 \\
\hline Preto & 30 & 32,6 & 20 & 35,7 \\
\hline Pardo & 38 & 41,3 & 26 & 46,4 \\
\hline \multicolumn{5}{|l|}{ Idade (anos) } \\
\hline$<31$ & 8 & 8,7 & 2 & 3,6 \\
\hline $31-50$ & 68 & 73,9 & 44 & 78,5 \\
\hline$>50$ & 16 & 17,4 & 10 & 17,9 \\
\hline \multicolumn{5}{|l|}{ Anos de estudo } \\
\hline Nenhum & 20 & 21,7 & 14 & 25,0 \\
\hline $1-2$ & 7 & 7,6 & 6 & 10,8 \\
\hline 3 ou mais & 65 & 70,7 & 36 & 64,2 \\
\hline \multicolumn{5}{|l|}{ Renda mensal } \\
\hline$<\mathrm{R} \$ 101,00$ & 17 & 18,5 & 10 & 17,9 \\
\hline $\mathrm{R} \$ 101,00$ a $\mathrm{R} \$ 200,00$ & 53 & 57,6 & 29 & 51,8 \\
\hline$>\mathrm{R} \$ 200,00$ & 22 & 23,9 & 17 & 30,3 \\
\hline \multicolumn{5}{|c|}{ Tempo de profissão (anos) } \\
\hline$<10$ & 22 & 24,0 & 12 & 21,4 \\
\hline 10 ou mais & 70 & 76,0 & 44 & 78,6 \\
\hline \multicolumn{5}{|c|}{ Jornada diária de trabalho (horas) } \\
\hline Até 12 & 38 & 41,3 & 24 & 42,9 \\
\hline Acima de 12 & 54 & 58,7 & 32 & 57,1 \\
\hline \multicolumn{5}{|c|}{ Atividade laboral paralela } \\
\hline $\operatorname{Sim}$ & 21 & 22,9 & 11 & 19,6 \\
\hline Não & 71 & 77,1 & 45 & 80,4 \\
\hline \multicolumn{5}{|c|}{ Contribui regularmente para a Previdência Social? } \\
\hline Sim & 4 & 4,3 & 1 & 1,8 \\
\hline Não & 88 & 95,7 & 55 & 98,2 \\
\hline Total & 92 & 100,0 & 56 & 100,0 \\
\hline
\end{tabular}




\section{Tabela 2}

Características dos acidentes do trabalho referidos pelos pescadores profissionais artesanais da Colônia ASPESCA. Araguacema, Tocantins, Brasil, 2002.

\begin{tabular}{|c|c|c|}
\hline Variável & $\mathbf{n}$ & $\%$ \\
\hline \multicolumn{3}{|l|}{ Tipo de acidente } \\
\hline Típico & 56 & 100,0 \\
\hline Trajeto & 0 & 0,0 \\
\hline \multicolumn{3}{|l|}{ Causa imediata do acidente } \\
\hline Lesão por animal do ambiente aquático & 48 & 86,0 \\
\hline Corte com faca ou tesoura & 3 & 5,0 \\
\hline Lesão por anzol & 2 & 3,0 \\
\hline Acidente com rede ou tarrafa & 1 & 2,0 \\
\hline Traumas por barco a remo & 1 & 2,0 \\
\hline Lesão por motor de barco & 1 & 2,0 \\
\hline \multicolumn{3}{|l|}{ Período do dia } \\
\hline Manhã & 21 & 37,5 \\
\hline Tarde & 17 & 30,4 \\
\hline Noite & 18 & 32,1 \\
\hline \multicolumn{3}{|l|}{ Atividade na hora do acidente } \\
\hline Retirando peixe do anzol ou rede & 26 & 46,4 \\
\hline Armando ou recolhendo material de pesca & 14 & 25,0 \\
\hline Operando ou conduzindo embarcação & 8 & 14,3 \\
\hline Manipulando ou transportando pescado & 7 & 12,5 \\
\hline Preparando isca & 1 & 1,8 \\
\hline \multicolumn{3}{|l|}{ Procura por atendimento médico } \\
\hline Sim & 7 & 12,5 \\
\hline Não & 49 & 87,5 \\
\hline \multicolumn{3}{|l|}{ Região anatômica atingida } \\
\hline Membro superior & 27 & 48,2 \\
\hline Membro inferior & 22 & 39,3 \\
\hline Outros (cabeça, pescoço e tronco) & 7 & 12,5 \\
\hline \multicolumn{3}{|l|}{ Emprego de tratamento popular } \\
\hline Sim & 37 & 66,1 \\
\hline Não & 19 & 33,9 \\
\hline Total & 56 & 100,0 \\
\hline
\end{tabular}

taram ter sofrido acidente e procurado atendimento médico, essa proporção foi de $71,4 \%$. Na Tabela 4 são relacionados os tipos de tratamentos populares utilizados para o trato das lesões.

Em 3,6\% dos casos onde acidentes foram referidos, as lesões evoluíram para cura com seqüelas. Em todas essas situações, a perda parcial de movimento do membro atingido foi o caso. Amputações não foram relatadas.

Com relação ao tempo de incapacidade para o trabalho em decorrência dos acidentes, a maioria dos entrevistados disse não ter tido problemas para desenvolver suas atividades laborais. No entanto, $8,9 \%$ relataram ter ficado impossibilitados de trabalhar por mais de um mês.

Em um desses casos, uma vítima de acidente por mandubé (Ageneiosus sp.) ficou cerca de um ano afastado do trabalho. Em nenhum caso o seguro acidente foi solicitado/recebido.

\section{Discussão}

Inicialmente, cumpre salientar que a estimativa de proporção de incidência de acidentes do trabalho aqui apresentada, $85,9 \%$ ao ano, é altíssima. Estudos sobre incidência de acidentes laborais entre trabalhadores urbanos costumam apresentar estimativas em torno de 5,0\% ao ano, já corrigida a subnotificação do Sistema CAT e incorporando as ocorrências no mercado informal da economia 1,2,15.

No Brasil, estudos envolvendo comunidades pesqueiras tendem a enfocar os aspectos referentes ao cotidiano das atividades de pesca e as relações de gênero que se estabelecem nos domínios espaciais desse universo, sem, contudo, abordar de maneira mais ampla as interações entre os pescadores, a atividade laboral e o meio. As injúrias sofridas pelos pescadores durante ou a caminho do trabalho constituem um bom exemplo dessas interações, mas a carência de estudos na área dificulta sua discussão. Esse fato, provavelmente associado com as dificuldades logísticas da coleta de dados, encontra suporte em estudos como os realizados por Almeida \& Rocha 18, Carvalho 19 e Haddad Jr. 12,20 , que pesquisaram acidentes por peixes em diferentes segmentos da população, sobretudo entre pescadores.

Deixar a terra firme e se aventurar em busca de sustento sem a certeza de que irá realizar uma boa pescaria, passou a ser uma preocupação cada vez mais presente na vida dos pescadores e essa parece ser uma condição que começa a trazer prejuízos para a saúde desses trabalhadores. Em estudo realizado na região de 
Belém, Pará, Bezerra 21 demonstrou que os pescadores apresentam mais problemas psiquiátricos e de consumo de álcool e tabaco que outros moradores do mesmo local. Segundo o autor, a maior parte desses problemas está, entre outros fatores, relacionada com a baixa remuneração e com as condições de trabalho oferecidas pela atividade.

Entre os pescadores do Município de Araguacema, apesar do consumo de álcool e tabaco não ter sido sistematicamente investigado, foi possível observar uma grande quantidade de pescadores que possuíam o hábito de beber e fumar. A dura jornada de trabalho, que inclui a exposição a fatores ambientais, como a temperatura e o terrível contato com insetos hematófagos, entre outros, torna a aguardente, denominada de "cachaça" pelos pescadores, um equipamento quase que obrigatório nas pescarias, pois além de "esquentar" e "espantar os mosquitos", é muito utilizada para a limpeza de ferimentos sofridos durante o exercício da atividade pesqueira. Esses ferimentos ou "ofensas", objeto de estudo da presente investigação, demonstraram ser acontecimentos freqüentes e às vezes graves, embora os pescadores pareçam minimizá-los pelo receio em assumir um estado de fragilidade que um evento como esse pode impor.

Por fim, como relatado por Haddad Jr. 20, deve ser passada a noção de que a maioria dos animais do ambiente aquático citada neste trabalho não é agressiva, utilizando seus ferrões, dentes ou espículas apenas como meio de defesa.

\section{Tabela 3}

Relação dos animais do ambiente aquático envolvidos nos acidentes do trabalho relatados pelos pescadores profissionais artesanais da Colônia ASPESCA. Araguacema, Tocantins, Brasil, 2002.

\begin{tabular}{lrr}
\hline Espécie & $\mathbf{n}$ & $\%$ \\
\hline Piranha (Pygocentrus nattereri) & 13 & 27,0 \\
Mandi (Pimelodus sp.) & 7 & 14,6 \\
Arraia de fogo (Potamotrygon sp.) & 7 & 14,6 \\
Surubim (Pseudoplatystoma sp.) & 4 & 8,3 \\
Tucunaré (Cichla sp.) & 4 & 8,3 \\
Bicuda (Boulengerella sp.) & 3 & 6,2 \\
Pacu (Myleus sp.) & 2 & 4,2 \\
Poraquê (Electrophorus electricus) & 2 & 4,2 \\
Cachorra (Cynodontidae) & 1 & 2,1 \\
Candiru (Trychomycteridae) & 1 & 2,1 \\
Armau (Pterodoras sp.) & 1 & 2,1 \\
Boca Larga (Ageneiosus) & 1 & 2,1 \\
Gaivota & 1 & 2,1 \\
Jacaré Açu (Melanosuchus niger) & 1 & 2,1 \\
Total & 48 & 100,0 \\
\hline
\end{tabular}

Tabela 4

Materiais utilizados nos tratamentos populares empregados pelos pescadores profissionais artesanais da Colônia ASPESCA. Araguacema, Tocantins, Brasil, 2002*

\begin{tabular}{lrr}
\hline Material utilizado & $\mathbf{n}$ & $\%$ \\
\hline Aguardente & 12 & 32,4 \\
Partes de peixes & 8 & 21,6 \\
Urina & 5 & 13,5 \\
Gelo & 4 & 10,8 \\
Álcool de cozinha & 3 & 8,1 \\
Plantas & 2 & 5,5 \\
Outros (pó de café, café quente, gasolina) & 3 & 8,1 \\
Total & 37 & 100,0 \\
\hline
\end{tabular}

* Em 40,5\% dos tratamentos populares houve a utilização conjunta de pedaços de pano ou camisetas para conter sangramentos. 


\section{Resumo}

Este é um estudo transversal, com componente retrospectivo, investigando a ocorrência de acidentes do trabalho entre pescadores profissionais artesanais da região do médio Rio Araguaia, Tocantins, Brasil. Entre junho e agosto de 2002, foram entrevistados pescadores do Município de Araguacema, com respeito à organização de suas atividades de trabalho e à ocorrência de acidentes do trabalho nos últimos seis meses. Dos 92 pescadores que participaram do estudo, 56 relataram ter sofrido acidente. A proporção de incidência de acidentes obtida foi de 82,6\% ao ano. Cerca de 95,7\% dos entrevistados referiram não contribuir regularmente para a Previdência Social e não estarem cientes sobre seus direitos e deveres previdenciários. Entre os pescadores que referiram acidentes, essa proporção foi de $98,2 \%$. Aproximadamente $23,0 \%$ dos pescadores estudados relataram possuir outra atividade laboral paralela, principalmente como pedreiro $(47,6 \%)$ e guia de pesca (23,9\%). As injúrias por animais do ambiente aquático foram a principal causa de acidente relatada pelos pescadores, perfazendo cerca de $86,0 \%$ dos casos. Percebe-se, diante dos resultados, que os acidentes por animais do ambiente aquático são um importante agravo à saúde, provocando, em alguns casos, incapacidade temporária para o trabalho.

Acidentes de Trabalho; Trabalhadores; Fauna Aquática; Incidência

\section{Colaboradores}

D. Garrone Neto redigiu o artigo. R. C. Cordeiro e V. Haddad Jr. colaboraram na elaboração do manuscrito todo.

\section{Agradecimentos}

Os autores são gratos ao Frei Donizete Pereira de Castro e a Irmã Oneida das Graças Resende pelo apoio logístico dado durante o período da coleta de dados; a presidência da Associação dos Pescadores de Araguacema - Colônia ASPESCA e a seus respectivos membros, pela receptividade e colaboração no estudo; aos funcionários do Hospital Municipal de Araguacema, pelas informações sobre as ocorrências com pescadores atendidos na unidade; ao Dr. Francisco Oscar de Siqueira França e a Dra. Maria José Alencar Vilela, pelas valiosas sugestões; a Coordenação de Aperfeiçoamento de Pessoal de Nível Superior (CAPES), por financiar parte da pesquisa.

\section{Referências}

1. Binder MCP, Cordeiro R. Sub-registro de acidentes do trabalho em localidade do Estado de São Paulo, 1997. Rev Saúde Pública 2003; 37:409-16.

2. Santana VS, Loomis D. Informal jobs and non-fatal occupational injuries. Ann Occup Hyg 2004; 48:147-57.

3. Organização Internacional do Trabalho. Anuário de estatísticas do trabalho. Brasília: Organização Internacional do Trabalho; 2000.

4. Almeida IM, Binder MCP, Wludarski SL. Estudo da evolução dos acidentes do trabalho registrados pela Previdência Social no período de 1995 a 1999, em Botucatu, São Paulo. Cad Saúde Pública 2001; 17:915-24

5. Wünsch Filho V. Reestruturação produtiva e acidentes de trabalho no Brasil: estrutura e tendência. Cad Saúde Pública 1999; 19:41-51.

6. Alves S, Luchesi G. Acidentes do trabalho e doenças profissionais no Brasil: a precariedade das informações. Inf Epidemiol SUS 1992; 1:5-19.

7. Ministério da Previdência e Assistência Social. Anuário estatístico de acidentes do trabalho 2001. http://www.mpas.gov.br/12_08_01_01_01.asp (acessado em 13/Mar/2002).

8. Possas C. Avaliação da situação atual do sistema de informação sobre doenças e acidentes do trabalho no âmbito da Previdência Social brasileira e propostas para sua reformulação. Rev Bras Saúde Ocup 1987; 15:43-67.

9. Johansen B. Pesca profissional: contribuições, reivindicações e perspectivas. http://www.sfrancisco.bio.br/noticias/debate.htm (acessado em 03/Nov/2002).

10. Kater G. Pescador - herói do mar. Cadernos do Terceiro Mundo 2001; 227:35-42.

11. Ministério da Previdência e Assistência Social. Literatura leva pescador a descobrir Previdência. http://www.previdenciasocial.gov.br/agrev/Most raNoticia.asp $?$ Id $=11897 \& A T V D=1 \& x B o t a o=1$ (acessado em 10/Jul/2003).

12. Haddad Jr. V. Avaliação epidemiológica, clínica e terapêutica de acidentes provocados por animais peçonhentos marinhos na região Sudeste do Brasil [Tese de Doutorado]. São Paulo: Universidade Federal de São Paulo; 2000.

13. Instituto Brasileiro do Meio Ambiente e dos Recursos Naturais Renováveis. Estatística da pesca 2000. Brasil - grandes regiões e unidades da federação. Brasília: Instituto Brasileiro do Meio Ambiente e dos Recursos Naturais Renováveis; 2000.

14. Fehlberg MF, Santos IS, Tomasi E. Acidentes de trabalho na zona rural de Pelotas, Rio Grande do Sul: um estudo transversal de base populacional. Cad Saúde Pública 2001; 17:1375-81.

15. Cordeiro R, Sakate M, Clemente APG, Diniz CS, Donalisio MR. Subnotificação de acidentes do trabalho em localidade do sudeste do Brasil. Rev Saúde Pública; no prelo.

16. Ministério do Trabalho e Emprego. Classificação brasileira de ocupações (CBO2002). http://www. mtecbo.gov.br (acessado em 21/Mai/2002).

17. Santana VS, Cordeiro R. Detecção de agravos à saúde relacionados com o trabalho em estudos epidemiológicos. In: Mendes R, organizador. Pa- 
tologia do trabalho. 2a Ed. São Paulo: Atheneu; 2002. p. 199-229.

18. Almeida V, Rocha C. Registro dos acidentes com peixes peçonhentos e/ou venenosos. Rev Soc Bras Toxicol 1989; 2:49-50.

19. Carvalho MSI. Pescadores e ofensas. Percepções e práticas relativas aos acidentes por peixes venenosos na comunidade de pescadores de Siribinha, Bahia [Dissertação de Mestrado]. Salvador: Instituto de Saúde Coletiva, Universidade Federal da Bahia; 1999.

20. Haddad Jr. V. Atlas de animais aquáticos perigosos do Brasil: guia médico de diagnóstico e tratamento de acidentes. São Paulo: Roca; 2000.

21. Bezerra B. Distúrbios psiquiátricos em pescadores da Amazônia. Jornal da Paulista 2002; 168:1-2.

Recebido em 06/Ago/2004

Versão final reapresentada em 07/Dez/2004

Aprovado em 10/Dez/2004 